\title{
MOBILE APPLICATION DEVELOPMENT METHOdOLOGIES ADOPTED IN OMANI MARKET: A COMPARATIVE STUDY
}

\author{
Seiren Al-Ratrout ${ }^{1}$, Omar Husain Tarawneh ${ }^{1}$, Moath HusniAltarawneh ${ }^{2}$ and \\ Mejhem Yosef Altarawneh ${ }^{2}$ \\ ${ }^{1}$ Dept. of Information Technology, Al zahra College for Women, Oman \\ ${ }^{2}$ Dept. of Information Technology, The World Islamic Sciences and Education \\ University,Jordan.
}

\begin{abstract}
Popularity of mobile phones and huge growing for mobile applications make developers in need for flexible software process, which can deal with many challenges facing the mobile app development process. These challenges include: volatility of requirements, strong user involvement, development time tightness, process simplicity, and production of valuable software in low cost. This research study investigates the current mobile app development approaches adopted in Omani market and provides a comparison between existing methods. The results reveal that Agile approach is the most popular model for mobile software engineering in Omani, as it naturally fits most of the applications required in this market. The study also discusses various agile process models such as Scrum, XP, Lean, DSDM, and others. It is concluded that $X P$ model is the most preferable model used by Omani developers due to its dynamic and adaptive nature for different mobile app processes. The study provides also a series of recommendations for mobile app developers which should help in selecting the most appropriate method that suits the targeted market sector.
\end{abstract}

\section{Keywords}

Development approach, Mobile application, Agile, XP, survey, Oman.

\section{INTRODUCTION}

Over the last decade, mobile phones play an important role in the economy and seem to be the future of the business [1 and 2]. Mobile applications or mobile app are evolving rapidly, many people are doing their activities through their mobile phones, and many companies are trying to build their application in mobile based, there is huge growing and competition in the mobile app market [2 and 3]. However, as mobile applications become more complex, and moving to more business critical uses, mobile app development process -or mobile software engineeringbecomes promising areas for software engineering research. It will be essential to recognize the most suitable and applicable mobile software engineering processes, where such demand has striven developers to employ different mobile software engineering methodologies [4-6].

DOI: $10.5121 /$ ijsea.2019.10202 
Software engineering is the application of engineering principles to the software design, development and maintenance. Software development methodology is a framework used to plan, structure, and control the software process [7]. Selecting appropriate software development methodology leads to rapid application delivery, cost reduction, and avoiding critical risks. Further, it provides the developer with the best practices for producing software app that meet the real customer needs. Generally, mobile app development process consists of five phases; namely: initiation to understand requirements, design, development, acceptance for final release, and support which includes training, maintenance, and upgrade [8]. It is a critical task to control and manage the software process in order to ensure that the produced software app comprises of high degree of integrity, quality, as well as user satisfaction.

Many other challenges are facing the mobile app developers needed to be overcome [1, 2 and 9]; these challenges include: volatility of the requirements, strong user involvement since the early stages of the development, tightness of the development time, and development process simplicity [10]. A typical phenomenon challenges any software development is requirements changes, it might cause user dissatisfaction in case of restricting incoming changes, or cause delay in project delivery in case of allowing too many changes [11].

Thus, software development methodology to control the development process and deal with the challenges is essential to accomplish successful app production. Traditional methodologies that are used in the desktop application development might not be appropriate for mobile app development. Characteristics of mobile app are: short life cycles, short software development life cycles, limited hardware capabilities, easily updateable, downloaded quickly, lack of requirements description, and frequent change of requirements [12].

There is still lack of research and lack of understanding and analyzing the concerns and challenges that may occur in mobile app development process. Few formal research about mobile app engineering have been done until now, [16 and 18], and it was hard to find evidence of any study that highlights these issues conducted in Omani market. Although the advantages in mobile technology and the adoption of mobile services have a big influence in Oman [13-15].

The objectives of this study are to gain better understanding of development practices for mobile apps, to highlight the methodologies adopted currently in the Omani market. Also to recommend the best practices to be employed for mobile app engineering which promising to help the targeted market sector developers.

The rest of the paper is organized as follows: Section 2 presents a review of related literatures, the research methodology is presented in Section 3. A comparative study in Omani market of current mobile development approaches is analyzed and discussed in Section 4. Series of recommendations for mobile application developers are presented in Section 5 .Section 6 concludes the paper.

\section{REVIEW OF RELATED LITERATURES}

Several studies have been conducted about mobile development methods. In [16], the authors aimed to highlight the current trends in mobile application development methodology through a survey related to mobile application development process. In this survey, various Agile 
approaches such as XP, Scrum, and Lean have been evaluated for their significance in mobile applications development. The study showed that Agile methods have the potential to help in delivering enhanced speed and quality, which naturally fit mobile applications development needs and suitable for mobile development projects.

In [17], Agile - SCRUM practices have been used to develop a light-weight Android application, where changes in requirements could be accommodated and technical skills upgraded to adapt to technologies and tools used in the project. In that project a secure backup application on Android platform developed using important features from Agile-SCRUM methodology. The researchers concluded that Agile-SCRUM is the best to suit requirements of android software development, since they could enhanced quality assurance measurements through daily SCRUM meetings, subversioning framework, process-wide reviews, and feedback sessions.

Although Agile-Scrum has been observed obviously in the scope of mobile software development, a case study in which XP and SCRUM were evaluated from educational perspectives in a university setting. Two groups of students developed their own version of the same mobile application; one group used scrum, and the other group used XP. The results of that study revealed that both SCRUM and Extreme Programming produce good quality software in a short period of time. However, in regards to the changing of requirements, XP team accepted the changes easier than the SCRUM team [18].

Farrukh and Tariq [19] stated that hybrid Agile methodologies are ideal to overcome many limitations in today's mobile application development process. In other words, each agile approach has its own shortcoming, therefore a hybrid of two different methodologies such as scrum and XP should be suitable for most of the small and large projects. In such projects, the customers do not have clear requirements which complicate the development process. Therefore, scrum-XP hybrid methodology offers high level of communication among all team members and customers which results in a quick reaction on customer's changes in requirements and possibility to adapt the program to users without any loss.

In [20], it was shown that combining the strength of Scrum, XP and Lean is an ideal mobile application development methodology instead of applying any one agile methods solely. Cunha et al. [21] integrated Scrum with Lean Six Sigma and proposed SLeSS. Scrum is used for software development and project management even for complex projects while Lean Six Sigma (LSS) reducing defects and eliminating waste provide better quality product. It provides continuous process improvements.

ALP-mobile is another proposed process model which combines elements of Scrum, Kanban and eXtreme Programming (XP). This model was introduced to Austrian experts in the field of mobile application development, and the feedback regarding the flexibility in the development process was very positive as shown in the results. [22]

Although, there are many research studies conducted on mobile app development methods, it is hard to find evidence of any study that highlights the concerns of mobile app development in Omani market. Bear in mind that the adoption of mobile services have a big influence on Oman economy [13-15]. 
International Journal of Software Engineering \& Applications (IJSEA), Vol.10, No.2, March 2019

\section{RESEARCH METHODOLOGY}

Inductive research approach has been adopted in this study, starting from collecting data and observations of individual cases to generating or inferring broad general ideas and theories. The process of conducting this study involves the following activities:

1. Data collection: face-to-face survey has been done through interviewing mobile app developers from Omani market. Forty-Four different mobile apps have been investigated, serving in different society and market sectors. The targeted sectors include education, banking, marketing, communication, management, people with disabilities, transportation, and restaurants. This variety in the applications is recommended in order to investigate different and real needs of the current market. The interview questions are intended to identify the type of application, development team size, app users, and expose the adopted development approach, plus explanation with advantages for this selection.

2. Data analyzes: the survey data has been analyzed to find the most popular mobile app engineering currently used in the Oman; qualitative analyses has been used to analyse the collected data.

3. Recommendations: series of recommendations has been suggested for Omani market mobile app developers, which should help in selecting the most appropriate method that suits the targeted market sector.

\section{ANALYSIS}

This research investigates the most used mobile app development approaches that are being applied recently in the Omani market. These development approaches include waterfall, agile, spiral and prototype methodologies. The investigation is started by conducting a survey in Omani market through face-to-face interviewing mobile application developers. The survey covered Forty-Four mobile applications which are serving different society and market sectors as shown in figure1. This variety of mobile app aimed to help examining and observing varying needs of different current market organizations. The targeted sectors include education, banking, marketing, social communication, management, and social services such as App for disabled people, transportation, and restaurants.

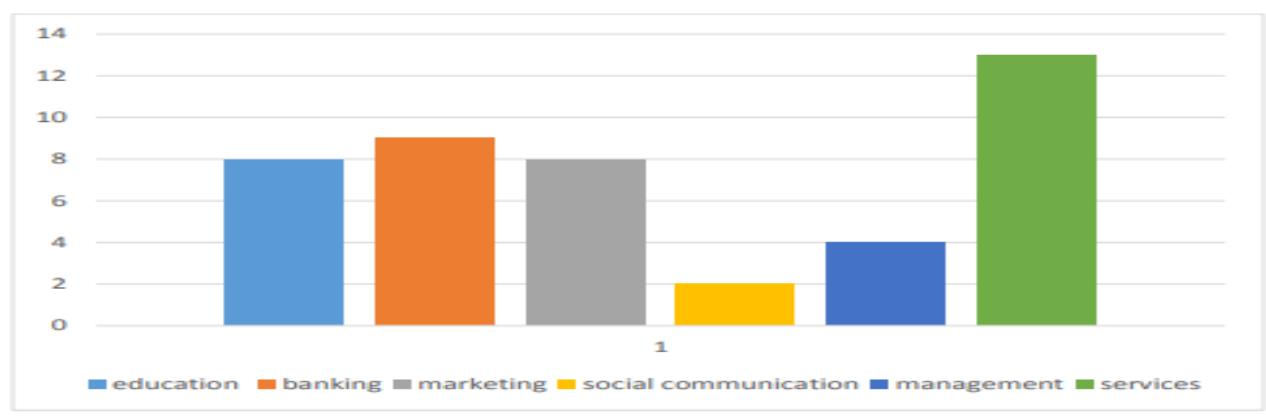

Figure 1: Mobile Application Types investigated in this survey 
After analyzing the survey data shown in Figure 2- it is found that agile approach is the most preferable and usable methodology for mobile app development in Oman. The results also indicated that agile methodologies were adopted in more than $50 \%$ of the mobile app under this study. This is due to the fact that agile approach ensures a clear channel of communication between developers and clients. This kind of communication is crucial in industry which is characterized by its dynamics, high competition, and dealing with uncertain environment. Therefore, agile methodologies would help developers when customer's requirements are incomplete, stakeholder involvement are required, or when the development lifecycle and budgets are tight. It can be concluded that the agile approach is a natural fit for mobile app development in Oman.

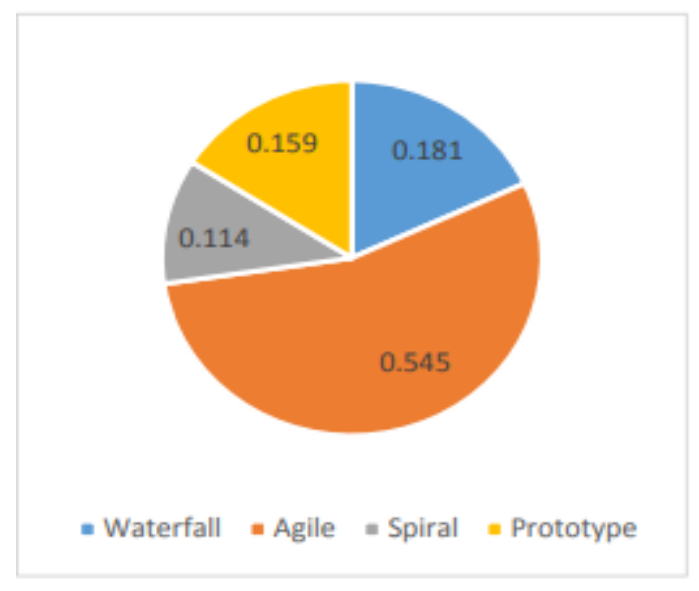

Figure 2. Mobile Application Development Methodologies

Agile development methodology refers to an iterative and incremental strategy that involves selforganizing teams working collaboratively to create the software. The term agile was introduced in the 1990s referring to flexibility in production systems [23]. The Agile Manifesto is a formal affirmation of 4 key values and 12 principles [24]. Implementing these key values and principles in mobile applications development should guarantee a proper interaction between the developer and the client which will result in involving the customer in the design and development stage and consequently delivering a working software. It will also help both developer and customer to respond to changes effectively. From the development perspective, agile methodologies should assure customer satisfaction since early stages, acceptance of requirements changing, cooperation between developers and clients, constant channel for team communications, and retain simplicity in the development process.

The study has also elaborated on various agile process models such as Scrum, XP, Lean, DSDM, and others, Table 1 shows various methods employed as agile approach along with their advantages and disadvantages. 
International Journal of Software Engineering \& Applications (IJSEA), Vol.10, No.2, March 2019

Table 1. Agile development Methods

\begin{tabular}{|c|c|c|c|}
\hline Agile method & Overview & Advantages & Disadvantages \\
\hline Scrum & $\begin{array}{l}\text { An } \\
\text { iterative and incremental } \\
\text { framework, feedback- } \\
\text { driven, where self- } \\
\text { organizing development } \\
\text { team works as a unit to } \\
\text { reach a common goal } \\
\text { 30-days release cycles }\end{array}$ & $\begin{array}{l}\text { - High communication } \\
\text { level with team member } \\
\text { - Client participation } \\
\text { - Self-organizing team } \\
\text { - Respect team members }\end{array}$ & $\begin{array}{ll}\text { - } & \text { lack of documentation } \\
- & \text { Close interaction } \\
- & \text { Lack of formal leader } \\
\text { - } & \text { specialized skills } \\
\text { and test plan } \\
\begin{array}{l}\text { track } \\
\text { tran easily get out off }\end{array}\end{array}$ \\
\hline $\begin{array}{l}\text { Lean } \\
\text { Development }\end{array}$ & $\begin{array}{l}\text { Optimizing efficiency and } \\
\text { minimizing producing } \\
\text { software that does not } \\
\text { address the customers' } \\
\text { needs }\end{array}$ & $\begin{array}{l}\text { - Waste Elimination } \\
\text { - No need for defining a } \\
\text { complete specification } \\
\text { - Deliver high-quality } \\
\text { systems quickly } \\
\text { - Optimizing delivered } \\
\text { business value }\end{array}$ & $\begin{array}{l}\text { - Difficult } r \\
\text { develop the system as } \\
\text { a single unit } \\
\text { - No } \quad \text { clear } \\
\text { requirements } \\
\text { definition } \\
\text { increase } \\
\text { implementation time. }\end{array}$ \\
\hline $\begin{array}{l}\text { Extreme } \\
\text { programming } \\
(\mathrm{XP})\end{array}$ & $\begin{array}{l}\text { frequent "releases" in short } \\
\text { development cycles, } \\
\text { customer driven development } \\
\text {, XP argue that the code is the } \\
\text { only truly important product } \\
\text { of the system development } \\
\text { process daily builds }\end{array}$ & $\begin{array}{l}\text { - Team communication, } \\
\text { - Technical practice } \\
\text { - } \text { Frequent feedback } \\
\text { actions } \\
\text { - Respect team members } \\
\text { - End user involvement } \\
\text { - Enhance quality } \\
\text { freedom and self-control } \\
\text { and innovation }\end{array}$ & $\begin{array}{l}\text { - } \quad \text { implicit design } \\
\text { - } \quad \text { hard to write good test } \\
\text { iterations } \\
\text { compromise quality } \\
\text { - } \quad \text { better applicable if all } \\
\text { team members can work at } \\
\text { the same location }\end{array}$ \\
\hline \begin{tabular}{|l|} 
Adaptive \\
Software \\
Development \\
(ASD)
\end{tabular} & $\begin{array}{l}\text { Adaptive practice, focuses on } \\
\text { collaboration and learning as a } \\
\text { technique to build complex } \\
\text { systems, Repeating series of } \\
\text { speculate, collaborate, and } \\
\text { learn cycles. }\end{array}$ & $\begin{array}{l}\text { - Extensive users involvement } \\
\text { - } \text { Requirements evolution } \\
\text { - } \text { High quality software } \\
\text { Early delivery. }\end{array}$ & $\begin{array}{l}\text { Extensive testing } \\
\text { increases the cost } \\
\text { - Projects become bigger } \\
\text { than they were visualized in } \\
\text { the initial stages. }\end{array}$ \\
\hline Agile Modeling & $\begin{array}{l}\text { The agile version of Model } \\
\text { Driven Development }\end{array}$ & $\begin{array}{l}\text { - Continuous attention to } \\
\text { technical excellence and good } \\
\text { design. } \\
\text { - Rapid, continuous } \\
\text { delivery of software. } \\
\text { - Customers, } \\
\text { developers and testers } \\
\text { interaction } \\
\text { - Welcoming late } \\
\text { changes in requirements }\end{array}$ & $\begin{array}{l}\text { - Lack of documentation } \\
\text { - Final outcome is not clear } \\
\text { - Fit only senior } \\
\text { programmers }\end{array}$ \\
\hline Crystal Methods & $\begin{array}{l}\text { Collection of agile } \\
\text { development methodologies, } \\
\text { focuses on six primary aspects: } \\
\text { people, interaction, } \\
\text { community, communication, } \\
\text { skills, } \\
\text { and talents. }\end{array}$ & $\begin{array}{l}\text { - Human-powered } \\
\text { - Adaptive } \\
\text { - Lightweight methodology }\end{array}$ & $\begin{array}{l}\text { - Critical decisions } \\
\text { regarding the architecture } \\
\text { of the application are made } \\
\text { by individuals and not by } \\
\text { the } \\
\text { entire team }\end{array}$ \\
\hline
\end{tabular}


International Journal of Software Engineering \& Applications (IJSEA), Vol.10, No.2, March 2019

\begin{tabular}{|c|c|c|c|}
\hline $\begin{array}{l}\text { Dynamic } \\
\text { System } \\
\text { Development } \\
\text { Methodology } \\
\text { (DSDM) }\end{array}$ & $\begin{array}{l}\text { Its origins the } \\
\text { RAD (Rapid } \\
\text { Application } \\
\text { Development) } \\
\text { Methodology. }\end{array}$ & $\begin{array}{l}\text { - Requirements continue to } \\
\text { evolve } \\
\text { - } \quad \text { Adheres strictly to } \\
\text { agreed timelines and } \\
\text { budget } \\
\text { - Stakeholders involvement } \\
\text { - Strong emphasis on } \\
\text { system testing } \\
\text { - realistic expectations }\end{array}$ & $\begin{array}{l}\text { - documentation are } \\
\text { complex and time } \\
\text { consuming } \\
\text { - can reduce the } \\
\text { robustness of code } \\
\text { - Skilled } \\
\text { developers/development } \\
\text { teams required }\end{array}$ \\
\hline \begin{tabular}{|l} 
Feature Driven \\
Development
\end{tabular} & $\begin{array}{l}\text { Oriented on resulting out small } \\
\text { blocks of client valued } \\
\text { functionality. }\end{array}$ & $\begin{array}{l}\text { - } \quad \text { Multiple teams } \\
\text { working in parallel } \\
\text { - } \quad \text { Tiny delivered S.W. } \\
\text { - } \quad \text { Map directly onto an } \\
\text { object domain model } \\
\text { - } \quad \text { Coded directly } \\
\text { - } \quad \text { Assembled in component sets } \\
\text { - }\end{array}$ & 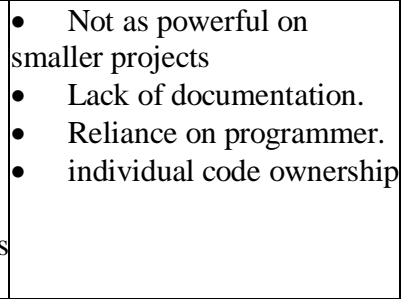 \\
\hline
\end{tabular}

Figure 3 shows the agile methodologies that are being used by mobile app developers in the Omani market. Although it can be noted that eXtreme Programming (XP) is most preferable development methodology, Scrum method is the most popular agile method in most applications [16]. XP involves breaking down the project into frequent releases in short development cycles, where each release contains some functionalities developed in simple code and tested within distinct phase before moving to the next part of project. This important feature made XP an attractive method to be used in Oman as the number of requirements is volatility and new requirements certainly introduced by the customer in different stages of the development. XP guarantees strong customer involvement in the development process, good communication inside of the teams, low cost for changes, and iterative cycles of development that will increase employee and users' satisfaction.

In-depth analysis of the collected data was done in order to elicit the impact of mobile app context and functionalities in the adopted development approach. The results reveal that most of the gaming and social communication applications are developed using XP. While developers of marketing, banking, transportation and management applications prefer to use Scrum. FDD and DSDM are commonly used for educational, disabilities, and restaurants applications.

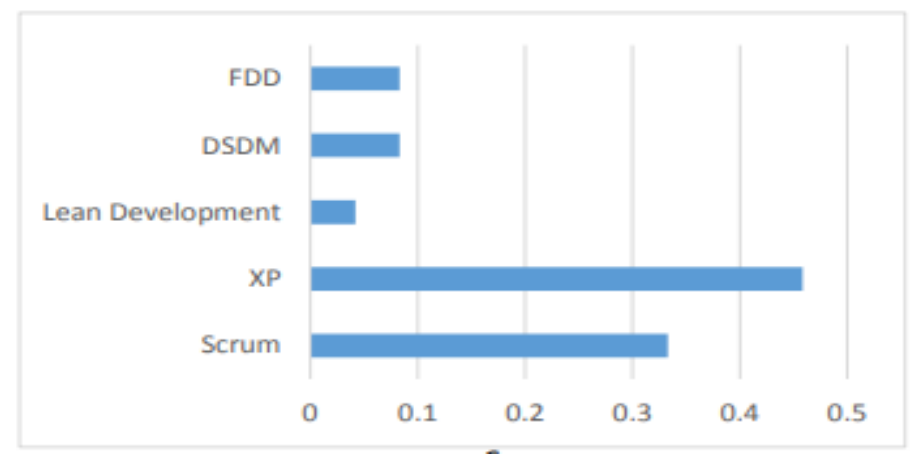

Figure 3. Mobile application development using different Agile Methodologies 
International Journal of Software Engineering \& Applications (IJSEA), Vol.10, No.2, March 2019

\section{RECOMMENDATIONS}

Another objective of this research study is to come up with a series of recommendations for mobile app developers in the Omani market. These recommendations should help mobile applications developers to select the most appropriate design method that suit the targeted market sector.

Based on the results revealed from the data analysis, it is suggested that implementing agile approaches are best suitable for the development of mobile apps. Furthermore, it is found that agile approaches are the best practice to be followed by the mobile apps developers as the findings show that agile approach is adopted in more than 50\% of the mobile app under this study. This is due to the fact that agile approach fits small teams, small development cycles, rapidly changing requirements, and continuous software integration and fast software delivery demands. However, the decision of choosing the right development methodology should be made on a case-by-case basis, where company's unique culture and organization will determine the appropriate agile methodology to be adopted, or based upon project's complexity and team size.

On the other hand, the context and functionalities of the applications could have a major impact on the adopted agile methodology. For instance, the results analysis of the questionnaire showed $\mathrm{XP}$ is best choice for gaming and social communication applications, while Scrum could be more preferable in marketing, banking, transportation and management applications.

The authors also believe that mixture of different agile processes is promising to enhance software engineering flexibility that should overcome many challenges. It also provides the developer with the best practices to implement mobile app that meet the customer requirements while not violating the realistic constraints. It would be more beneficial to consider the advantages of two or more combined agile methods to create a good mobile software product.

\section{CONCLUSION}

Mobile apps become the dominant phenomenon in the current market and economy, this research study aimed to highlight the most utilized mobile application development approach that is being used recently in the Omani market. Agile methodology was found to be most suitable for mobile app development as they accept changes easily, support cooperation between developers and clients, reduce delivery time, and simplify the development process. However, it has been observed in this research study that using AgileXP methodology is the most adopted method. XP guarantees strong customer involvement, good communication inside the teams, and incorporating new requirements easily that will increase employee satisfaction and retention. Methodologies for mobile app development are still being released and employed. There is no hard or fast rule that helps to choose the optimal methodology, however, it all depends on project context, complexity and team size. 
International Journal of Software Engineering \& Applications (IJSEA), Vol.10, No.2, March 2019

\section{REFERENCES}

[1] N. Ajit Kumar, K.T. Hari Krishna , Prof. Manjula R, " Challenges and Best Practices in Mobile Application Development", Imperial Journal of Interdisciplinary Research (IJIR), Vol-2, Issue-12, 2016

[2] Naila Kousar, Muhammad Sheraz, Aramghan Sarwar, Burhan Mohy-ud-din, Ayesha Shahid, "Software Engineering: Challenges and their Solution in Mobile App Development", (IJACSA) International Journal of Advanced Computer Science and Applications, Vol. 9, No. 1, 2018.

[3] Anthony I. Wasserman, "Software Engineering Issues for Mobile Application Development" Proceedings of the Workshop on Future of Software Engineering Research (FoSER), at the 18th ACM, 2010.

[4] Luis Corral, Alberto Sillitti, Giancarlo Succi, "Software Development Processes for Mobile Systems, Is Agile Really Taking Over the Business?" 1st International Workshop on the Engineering of Mobile-Enabled Systems (MOBS), 2013.

[5] V. Rahmimian and R. Ramsin, "Designing an Agile Methodology for Mobile Software Development: A hybrid Method Engineering Approach", in proceedings of second international conference on Research Challenges in Information Science, RCIS (2008). Marrakech, 2008, pp. 337- 342.

[6] A.C. Spataru, "Agile Development Methods for Mobile Applications", PhD Thesis, University of Edinburgh, the University Of Edinburg, Edinburg, 2010.

[7] Giner Alor-ernández, Viviana Yarel Rosales-Morales, and Luis Omar Colombo-Mendoza, "Frameworks, Methodologies, and Tools for Developing Rich Internet Applications", Information Science Reference, an imprint of IGI Global, 2015.

[8] Anureet Kaur, "Review on Agile Approach to Mobile Application Development", International Journal of Computing and Technology, Volume 3, Issue 4, April 2016.

[9] Ali Mesbah ; Philippe Kruchten, "Real Challenges in Mobile App Development, Mona Erfani Joorabchi “, ACM/IEEE International Symposium on Empirical Software Engineering and Measurement (ESEM), 2013.

[10] Mudasir M Kirmani, "Agile Methods for Mobile Application Gevelopment: A comparative analysis", International Journal of Advanced Research in Computer Science, Volume 8, No. 5, May-June 2017.

[11] Jalal Shah, Nazri Kama and Nur Azaliah A Bakar, "A Novel Effort Estimation Model For Software Requirement Changes During Software Development Phase", International Journal of Software Engineering \& Applications (IJSEA), Vol.9, No.6, November 2018

[12] Ganesh Prasad P, R Hamsini, Smitha G R, "Agile Development Methodology and Testing for Mobile Applications - A Survey", International Journal of New Technology and Research (IJNTR), ISSN:2454-4116,Volume-2, Issue-9, September 2016 Pages 98-101

[13] Sayed Jafar Naqvi, Hahed Al-Shihi, "Factors Affecting M-commerce Adoption in Oman using Technology Acceptance Modeling Approach", TEM Journal - Volume 3, Nov-2014. 
International Journal of Software Engineering \& Applications (IJSEA), Vol.10, No.2, March 2019

[14] Mohamed Sarrab, Ibtisam Al Shibli, and Nabeela Badursha, "An Empirical Study of Factors Driving the Adoption of Mobile Learning in Omani Higher Education", International Review of Research in Open and Distributed Learning, Volume 17, Number 4, June-2016

[15] Rakesh Belwal, Shweta Belwa, "Mobile Phone Usage Behavior of University Students in Oman", International Conference on New Trends in Information and Service Science, NISS '09. International Conference, 2009.

[16] Harleen K. Flora, Swati V. Chande, Xiaofeng Wang, "Adopting an Agile Approach for the Development of Mobile Applications", International Journal of Computer Applications (0975 - 8887) Volume 94 - No.17, May 2014.

[17] Shakira Banu Kaleel, Ssowjanya HariShankar, "Applying Agile Methodology in Mobile Software Engineering: Android Application Development and its Challenges", computer science Technical Report, 2013.

[18] Ramón Ventura Roque Hernández, Juan Antonio Herrera Izaguirre, Adán López Mendoza, Juan Manuel Salinas Escandón, "A Practical Approach to the Agile Development of Mobile Apps in the Classroom”, Innovación Educativa, ISSN: 1665-2673 vol. 17, número 73 | enero-abril, 2017.

[19] Farrukh Musa, Muhammad Ali Tariq, "Agile Methodology: Hybrid Approach Scrum and XP", International Journal of Scientific \& Engineering Research, Volume 8, Issue 4, April-2017.

[20] Anitha Ashishdeep, Jitendra Bhatia, Krunal Varma, "Software Process Models for Mobile Application Development: A Review”, IJCSC volume 7, 2016.

[21] Thiago Ferraz V. da Cunha, Valeria L. L. Dantas, Rossana M. C. Andrade, "SLeSS: A Scrum and Lean Six Sigma Integration Approach for the Development of Software Customization for Mobile Phones ”, Brazilian Symposium on Software Engineering, 2011.

[22] Raoul Vallon*, Lukas Wenzel, Martin E. Brüggemann, Thomas Grechenig, "An Agile and Lean Process Model for Mobile App Development: Case Study into Austrian Industry", Journal of Software, Volume 10, Number 11, November 2015.

[23] V. M. M. Thilak, S. R. Devadasan, and N. M. Sivaram, "A Literature Review on the Progression of Agile Manufacturing Paradigm and Its Scope of Application in Pump Industry", ScientificWorldJournal, 2015

[24] Harleen K. Flora , Dr. Swati V. Chande2, “ A Review and Analysis on Mobile Application Development Process Using Agile Methodologies", International Journal of Research in Computer Science, Volume 3 Issue 4 (2013). 